\title{
The Stress in the Relationship between Rider and Horse in Initial Training Equestrian Sport
}

\author{
Yuri Valev, PhD \\ Department of Technical and Ice Sports, "Equestrian Sport" Sector, National Sports Academy "Vasil Levski", \\ 1700 Sofia, Studentski Grad
}

\author{
*Corresponding Author: Yuri Valev, Department of Technical and Ice Sports, "Equestrian Sport" \\ Sector, National Sports Academy "Vasil Levski", 1700 Sofia, Studentski Grad, Bulgaria
}

\begin{abstract}
The stress in the relationship between rider and horse in initial training equestrian sport: With urbanization of society, hypodynamia of the rising generation, increase of the number of people with extra weight and unhealthy way of life more and more people in Bulgaria show keen interest in horse riding. In contrast to many other sports the initial training for horse riding may lead to experience of stress which impedes the training process and can even make the student withdraw. In this article we have tried to draw and systematize from the theory and practice the potential factors which may cause stress situations. An examination has been implemented which is designed to define the strength - "weight" of the fear reactions at different factors within the target groups for initial training. There is a developed methodological approach and exercises for getting over the stress impact.
\end{abstract}

Keywords: equestrian sport, relationship, initial training, stress

\section{INTRODUCTION}

With the urbanization of society, rising hypodynamics, overweight and unhealthy lifestyle in adolescents, interest in equestrian sport in Bulgaria is progressively increasing. Unlike many other sports, basic training in equestrian sport can get stressful situations that hamper the learning process or even give up.

This fundamental pedagogical problem of the initial training directed our attention to a pilot study of the stressful situations and the magnitude of the fear in connection with the implementation of the program "Sport for children in leisure time", "Initial training in equestrian sport", financed by the Ministry of Physical Education and sport for the period from 01.03.2015. Until 30.06.2015.

\section{EXPLANATION}

This fundamental pedagogical problem of the initial training directed our attention to a pilot study of the stressful situations and the magnitude of the fear in connection with the implementation of the program "Sport for children in leisure time", "Initial training in equestrian sport", financed by the Ministry of Physical Education and sport for the period from 01.03.2015. Until 30.06.2015. The aim of the study is to systematize and assess stressful situations due to the fear of initial training in equestrian sports with teenage children aged 7-14.

\section{Tasks of the study:}

1. Literary study and systematisation of stressful situations and fear of initial training in equestrian sport.

2. Investigation of the subjective opinion of participants in the program "Sports for children in the free time" on the factor weight of fear of the stressed situations in the initial training in equestrian sport.

\section{Methods of study:}

- Literary review and summary of the leading practice for the system of stress situations for the appearance of fear. 
- Inquiry survey at the beginning of Program Involvement (see Questionnaire), variation and graphical analysis for the subjective determination of the factor weight of the types of fear.

Contingent - 24 girls and boys participating in the Program were surveyed. Age from 7 to 14 years, average age -10 years.

Practical experience as a competitor, trainer and equestrian lecturer, as well as talks with prominent horse sport specialists, has enabled us to systematize 10 basic stress factors in initial horse training.

The magnitude of fear in the stress factors included in the survey 10 is determined by a variance analysis (see Table 1). The main conclusion of the results is that, in general, participants in this group, despite their young age, have indicated too low levels of stress factors. At the maximum fear scoring 10 , the average values for all factors are in the range of 0.64 balls to 2.79 balls, with the worst fear pointing to the Falling and Wounding Fatal Jumping Score of 2.79, which is quite naturally (see Table 1, Figure 1). Second is the "Fear of Loss of Balance and Fall in Gallop" - 2.45 balls (see Figure 1 and Table 1). Third is the "Fear of the Horse not to Fear" indicator - 2.21 (see Figure 1 and Table 1). Only 4 of the 10 factors have an expected maximum fear of 10 balls, and for single participants (see $\mathrm{X}_{\text {мах }}$ on Table 1).

Table1. Average Values and Variability of Factory Weight by Type of Fear in Primary Muscle Training in Scientific Year 2014-2015

\begin{tabular}{|c|c|c|c|c|c|c|c|c|c|}
\hline No & Indicators - Types of Strike & $\mathrm{X}$ & S & $\mathrm{V}$ & $\mathrm{X}_{\mathrm{MIN}}$ & $\mathrm{X}_{\mathrm{MAX}}$ & $\mathrm{R}$ & AS & EX \\
\hline 1 & Fear of "size of a horse" & 1.58 & 1.56 & & 1 & 8 & 7 & 3.48 & 13.20 \\
\hline 2 & Fear "horse NOT bite me" & 1.62 & 1.91 & & 1 & 10 & 9 & 4.08 & 17.73 \\
\hline 3 & Fear "The horse kicked me NOT" & 2.17 & 1.55 & & 1 & 6 & 5 & 1.60 & 1.70 \\
\hline 4 & Fear "horse not be afraid" & 2.21 & 2.10 & & 1 & 10 & 9 & 2.69 & 8.0 \\
\hline 5 & Fear "not to fall when climbing in the saddle" & 1.71 & 2.27 & & 1 & 10 & 9 & 3.27 & 9.86 \\
\hline \multirow[t]{3}{*}{6} & $\begin{array}{l}\text { Fear of "loss of balance and falling when } \\
\text { Allure": } \\
\text { 6.1. Fear of "loss of balance and falls": in walk } \\
\text { 6.2. Fear of "loss of balance and falls": in trot }\end{array}$ & 1.12 & 0.61 & & 1 & 4 & 3 & 4.90 & 24.00 \\
\hline & 6.3. Fear of "loss of balance and falls": in gallop & 1.75 & 1.26 & & 1 & 6 & 5 & 2.08 & 4.72 \\
\hline & & 2.45 & 1.77 & & 1 & 6 & 5 & 1.08 & 0.42 \\
\hline 7 & Fear will I be able to drive the horse while riding & 1.88 & 1.51 & & 1 & 6 & 5 & 1.96 & 3.16 \\
\hline 8 & Fear "can I stop the horse if necessary" & 2.00 & 2.02 & & 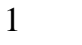 & 8 & 7 & 2.24 & 3.98 \\
\hline 9 & Fear of "falling and injuring in jumping training" & 2.79 & 2.32 & & 1 & 10 & 9 & 1.96 & 3.65 \\
\hline 10 & $\begin{array}{l}\text { Fear "will I do well in training, will the others } \\
\text { mock me" }\end{array}$ & 1.33 & 0.64 & & 1 & 3 & 2 & 1.79 & 2.20 \\
\hline
\end{tabular}

Factory Weight of Types of Straight in Initial Training Equestrian Sport 2015.

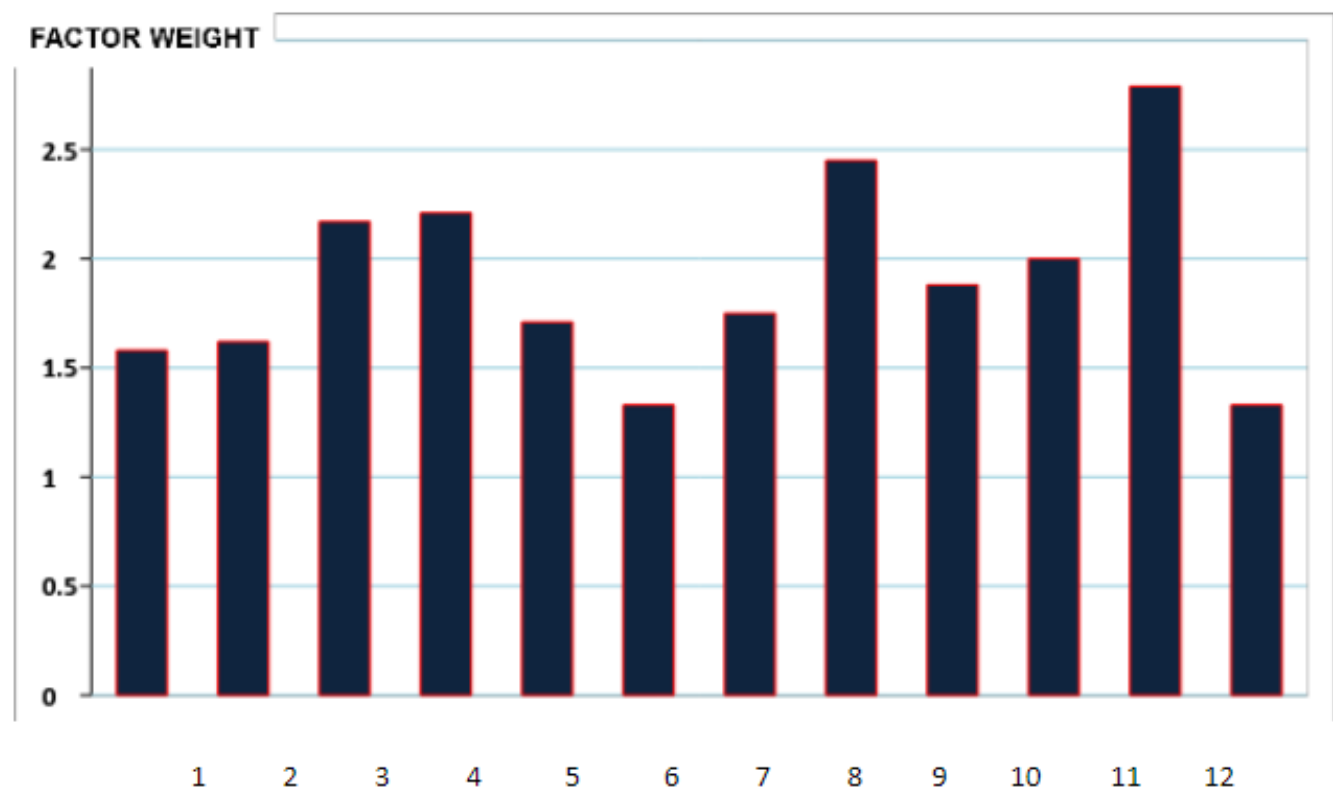

Figure1. Stress factors 
- Fear of "size of a horse"

- Fear "The horse NOT bite me"

- Fear "The horse kicked me NOT"

- Fear "horse not be afraid"

- Fear "not to fall when climbing in the saddle"

- Fear of "loss of balance and falls": in walk

- Fear of "loss of balance and falls": in trot

- Fear of "loss of balance and falls": in gallop

- Fear will I be able to drive the horse while riding

- Fear "can I stop the horse if necessary"

- Fear of "falling and injuring in jumping training"

- Fear "will I do well in training, will the others mock me"

\section{CONCLUSION}

From this study we can draw the following conclusions:

- The first conclusion of the survey conducted with the specific contingent of adolescent pupils participating in the Initial Training Program is that the level of anticipated cognitive responses at the beginning of the training is generally favorable for the group.

- With few individuals and factors, there are expectations of high stress reactions. This requires that individual elements be trained carefully and strictly individually with the individual participants.

- The level of fear on the "Fear of injury and injury in obstacle jumping training" is highest. Second is the "Fear of Loss of Balance and Fall in Gallop". Third is the "Fear the horse not afraid" indicator.

\section{REFERENCES}

[1] Valev, Y.D., Guide for the Elementary Training of Equestrian Sports Rider, S., NSA PRESS, 2013

[2] Valev Y.D, Visualized Methodology for Initial Training in Equestrian Sports, Dissertation Work, 2014

[3] Dimitrov, V., Changes of situational and personal anxiety in combat sportsmen after applying psychic effects. Sport and Science - extraordinary issue 4 / 2012г.123-127, 2012.

[4] Palikarski, G., Management of the Training Process in Elite Biathlonists, Dissertation Work, 2014

[5] Moira C. Harris \& Lis Clegg, Kompakt \& Visuell Reiten, London, Dorling Kindersley, 344 c. 2006

[6] Miesner S., M. Putz, M. Plewa, Richtlinien fur Reiter and Fahrer Band 1, Grundausbildung fur Reiter und Pferd, Warendorf, FNverlag, 224 c. Herausgeber Deutsche Reiterliche Vereinigung e. V. (FN), 2006

Citation: Yuri Valev, PhD. "The Stress in the Relationship between Rider and Horse in Initial Training Equestrian Sport." International Journal of Sports and Physical Education (IJSPE), vol 4, no. 1, 2018, pp. 1-3. doi:http://dx.doi.org/10.20431/2454-6380.0401001.

Copyright: (c) 2018 Authors. This is an open-access article distributed under the terms of the Creative Commons Attribution License, which permits unrestricted use, distribution, and reproduction in any medium, provided the original author and source are credited. 